\title{
Guidelines for Developing Competencies of Travel Agent Manager: A Comparative Study of Thailand and Laos
}

\author{
Chaiyong Chaicharoenthaweekit ${ }^{1} \&$ Krit Jarinto $^{2}$ \\ 1 Organization Development and Human Capability Management, Graduate School of Commerce, Burapha \\ University, Thailand \\ ${ }^{2}$ Graduate School of Commerce, Burapha University, Thailand \\ Correspondence: Chaiyong Chaicharoenthaweekit, 9/181 Soi 99/2 Mooban Pleno Eakachai-Kanchanapisek, \\ Bangbon, Bangkok 10150, Thailand. E-mail: chaicharoenthaweekit.c@gmail.com
}

Received: November 10, 2014

Accepted: December 10, 2014

Online Published: January 25, 2015

doi:10.5539/ibr.v8n2p143

URL: http://dx.doi.org/10.5539/ibr.v8n2p143

\begin{abstract}
This paper aims to develop guidelines for developing the competency required by a travel agent manager in the leisure and hospitality industry in Thailand and Laos. The conceptual framework is consisted of independent variables (core competency, common competency, and managerial competency) and dependent variable (guideline for Developing the competency of the manager). The data is collected from two sources: 1) 128 travel agents in both Laos and Thailand, and 2) additional 142 responses which are derived from snowball sampling, total 270 samples. Questionnaire is used as the data collecting tool. Multi-Layer Perceptron (MLP), which is a type of neural network statistic, is used for analysis and interpreting the factors to order prioritize of factors. The MLP is a mathematic network model which replicates neural network and it is used for anticipating the pattern of variables. It can be used for single variable analysis and multivariate analysis to describe variable significance and to map the variable linear.

The results suggest at least three significant indications for developing the competency of travel agent manager in Thailand and Laos. The findings also indicate that Thailand leisure and hospitality industry has focus on organizational culture development, change management, and self-management, while in Laos there is an emphasis on operation development, personnel administration, and product and service. This study shows what aspects of competency the managers of travel agencies in Thailand and in Laos are possessing and what are lacking. This helps the organizations to initiate the most suitable guideline for development the missing aspects. It can also be seen that both travel agencies in Thailand and in Laos do not pay sufficient attention on working competency nor strengthen their managers' competency to cope with either domestic competition or the more intense competition within and out of ASEAN region.
\end{abstract}

Keywords: guideline for competency development, neural network, travel agent manager

\section{Introduction}

After the ASEAN Declaration and Treaty of Amity and Cooperation have been signed among countries in Southeast Asian nations, AEC or ASEAN Economic Community is accelerated to exist fully activation by 2015 as a main pillar. This acceleration will increase the volumes of products, purchasing power, and labor in a variety of industries and service part which contribute around 1.2 billion in the year 2013. Professions in tourism, like others, needs to improve its competency to create competitive advantages. (Bunditkul, 2010). Tourism service was liberalized which is a consequence of AEC will have both positive and negative impacts on Thai tourism industry; therefore, it is necessary for tourism entrepreneurs to have a proper business plan for the change (Ministry of Tourism and Sports, 2011). And, the income Thailand and other ASEAN countries gain from tourism is very high; as a result, tourism plays a significant role in Thai and global economic systems in overall. (Mcintosh \& Goeldner, 1986).

A great number of businesses are related to tourism. The directly related businesses are such as travel agent, hotel, restaurant and etc. and those indirectly related businesses are local handicraft, construction work, and other supportive businesses. (Tesone, 2005) Hence, it can be realized that tourism is very important for both economic and social development of Thailand and that is the reason for Thailand to seek effective ways to improve the 
productivity of these businesses. Competency development of personnel especially travel agent manager is one of the possible ways to upgrade the competitiveness of the tourism of Thailand. This development can be divided into core competency, general competency, and managerial competency. (Ministry of Tourism \& Sports, 2011).

From reviewing of literature and related research, it can be stated that travel agent manager is one of the most important person in driving the organization to achieve the business goals effectively. Since, this position is also assigned to be one of the 32 jobs specified in ASEAN Standard for Tourism Professionals. It is necessary to examine competency of travel agent manager of Thailand, separated from other ASEAN member countries. Although there are a great number of research works studying elements of tourism in Thailand and others countries, but there is no research related to comparative guideline for developing the competency of travel agent manager in Thailand and Laos. Therefore, this is an interesting topic to be studied and the findings will provide information from related stakeholder to develop the competency of management level effectively. Which defines the conceptual framework is consisted of independent variables (core competency, common competency, and managerial competency) and dependent variable (guideline for improving the competency of the manager) for use in this study.

This paper shows what aspects of competency for travel agent manager in Thailand and in Laos are possessing and what are lacking. This helps the organizations to initiate the most suitable guideline for development the missing aspects. It can also be seen that both travel agencies in Thailand and in Laos do not pay sufficient attention on working competency nor strengthen their managers' competency to cope with either domestic competition or the more intense competition within and out of ASEAN region.

\subsection{Objective}

Therefore, the objective of this paper is to identify necessary know-how of being travel agents and develop a guideline for travel agents managers in Thailand and Laos.

\subsection{Benefit}

The research implication of this paper is that related to tourism industry can understand and propose a guideline for developing the competency of travel agent manager in Thailand and Laos.

\subsection{Conceptual Framework}

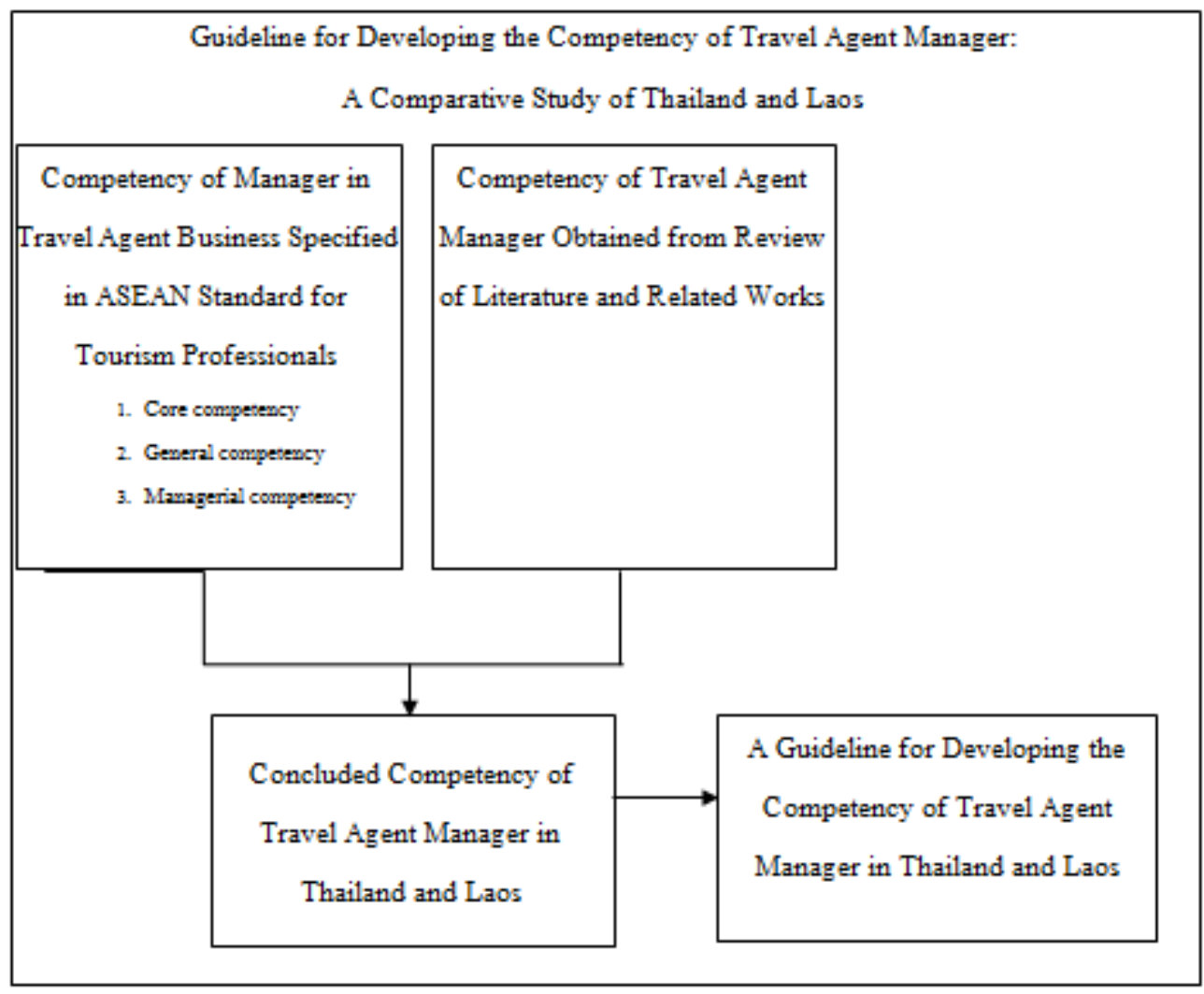

Figure 1. Conceptual framework 


\section{Literature Review}

(Alonderiene \& Navickiene, 2009) defined tourism industry development as life-long learning (LLL) which is a part of modern society. This is based on the fundamental of self-exploration themselves. Necessary competency for tourism industry is varied depending on the learner and environment. As same (Moura, 2013) also agrees upon the competency improvement that, to achieve the set goals on manager and staff learning, training, and improvement, emotional quotient which is comprised of self-awareness, self-regulation, motivation, empathy, and social skills is required. Similar to (Gaffar \& Setiyorini, 2010), they have highlighted development of communication skill and interpersonal relationship as an essential of tourism human resources development. And, to develop what is so called soft skills, it can perhaps be done by integrating various activities into tourism curriculum. Three skills are aimed for the development. The first one is self-management. This personal factor promotes teamwork skill or ability of an individual and it also effectively enhances interpersonal relationship between a particular individual and his/her co-workers. The second skill is learning from others. This is developed from examining the others or co-workers to facilitate the success of teamwork. The last skill is working skill or other job-related ability. This is referred to the specialty required for travel agency business and tourism industry such as omniscience of travel agency management. For this research, the meaning of tourism industry development is relied on work (Valachis, 2003) which neologized the meaning of tourism industry development, so the learning which emphasizes on the developments of skills and performance including management, marketing, human resources, technology, operation, and financial accounting, all should be emphasized. In addition, personal skills such as leadership, analytical thinking, and time management should not be left behind because these skills facilitate the success of learners and tourism business.

At the present, a number of definitions of managerial competency have been coined. (Boyatzis, 2008) seems to be one of the very first people studying the managerial competency and focusing on the operation which includes the ability of management in terms of operation goals set for administration efficiency. He has also scoped that this competency integrates abilities and skills of management, operation, leadership, human resources management, subordinate management, and interpersonal relationship. These qualifications can be found in the fundamental of management, planning, organization, control, motivation establishment, and coordination. As a result, it is important for an organization to explore what are the skills or ability needed to be strengthened or developed. Then, with the training design provided by the training manager, the support for those shortages should be systematically offered. Which paper (Kulisha, 2011) conducted a study in this field and the findings show that manager competency is influenced by 3 main elements including skill, knowledge, and attitude or (SKA). In addition, to develop manager personality requires personality competency (for example, identity development and change acceptance), and cross-cultural management competency (for example, communication skill development and cross-cultural behavior development). Moreover, there are also some other competencies facilitating the success of managers in service and tourism businesses are self-adjustment which is ability to cope with changes, information implementation ability, professional ability, and constant career development. (Thitthongkam \& Walsh, 2011) have added that tourism business is one of the important industries with rapid expansion and continuous growth. It offers a great number of jobs, so it is necessary for executives of travel agencies to learn and emphasize the labor quality and development. Manager is in the position where competency development and improvement is required to, at most, satisfy the tourist's needs.

Travel agent manager competency consists of 21 elements which are necessary to be accentuated; however, these 21 elements can be grouped up into: financial management, marketing analysis, quality management, risk and health management, mastery, team management, human resources management, tourism management, behavior perception, work environment management, computer skill, language proficiency, accommodation management, cuisine management, recreation management. (Cizel et al., 2007) From (Petkovski, 2011) paper, is added that knowledge, skills, position, and behavior as a key to be successful. In additional, managers have to handle with complicated and high pressure situations. And (Gultek et al., 2006) paper, additionally, have stated that training and development can possibly be beneficial for employees' work especially for the manager who plays the most important role in a travel agency. Therefore, objectives of a travel agency should include personal development, employee's expectation, and benefits from work. Since training and development facilitate employee's performance either at the present or in the future, training by standard organizations should be considered by the executive/owner/stakeholders to develop and to improve its employee's competency.

It also reveals that, to be professional in service business and tourism industry, both government and private sectors should provide training to meet professional standard, knowledge of service standard, expertise of work, business ethics, leadership, and organization structure. (Tesone \& Ricci, 2012; Weber et al., 2010) conducted a study related to implementation of knowledge, skill, and ability in competency evaluation for manager position 
development. There were 107 competency elements were used for the evaluation. Those 107 elements can be categorized into 1) communication, 2) efficiency management, 3) self-management 4) leadership, 5) interpersonal management, 6) (cross-cultural management, and 7) conflict management. In addition, (Whitelaw et al., 2009) have highlighted the essentials of becoming a good executive and a good manager that he/she needs to understand that tourism industry is convergent and uniquely different from other industries. Good design, determination, and understanding help to scope appropriate competency. A lot of studies have been conducted with their aims to explore requirements for travel agency managers to succeed their tasks. They findings indicate a variety of qualifications including steadiness, contribution, rationality, long-term strategic management, leadership, practicability of goals, understanding skill, and advanced communication skill. All these can be characterized into 5 requirements for managerial competency as follow.

1) Interpersonal relationship;

2) Leadership which encompasses ability to transform the thoughts of employees in every level into effective performance;

3) Creativity;

4) Human resources and financial management;

5) Technique which includes knowledge and skills necessary for the productions of tourism product and service.

From review of literature, it is found that all elements of competency development (change management, coordination, marketing, product and service development, personnel development, and etc.) are related to manager's performance. As a result, to improve the existing competency and to be able to fulfill the deficiency of competency, which is the manager is lacking.

\section{Research Methodology}

Mixed method is used for this research. The procedure follows by Qualitative first and Quantitative after.

Quantitative method is used for explaining the relationship and prioritizing the guidelines for the developing competency of Thailand and Laos. In-depth interview is used for collecting the data from instructors who teach subjects related to tourism, and tourism government officials; then, obtained data is ensured through data analysis using ATLAS ti 5.0 based on grounded theory to learn the content agreement of core competency, general competency, managerial competency, and the guideline for the development of manager competency. After that, qualitative method is employed to create a quantitative method.

Then, the questionnaire derived from in-depth interview, which is divided into 3 parts, the data from travel agents (161 in Thailand and 109 in Laos). Content validity (Index of item objective congruence) reliability (Cronbach's alpha) and ethical committee were passed, before being distributed.

\section{Data Analysis}

Descriptive statistics including frequency, percentage, mean, and standard deviation are used for data analysis. Inferential statistic, neural network is used for seeking the importance value of factors and for prioritizing the factors. Neural network is a type of statistic used for forecasting or estimating the characteristic of the factor. It works similarly to mathematic neural system used for processing the data with one and/or multi-factors which replicates human's neural system consisted of a great number of brain cells working coordinately. (Cheng, 1997) Therefore, the factor prioritization gained from multi-layer perceptron neural network clearly indicates the importance of each factor. Neural network can apply to many pure science and social science to analysis data (Payung, 2008) 
Table 1. Frequencies and percentage of demographic data

\begin{tabular}{|c|c|c|c|}
\hline \multirow{2}{*}{ Demographic Data of participant } & Thai & Laos & Total \\
\hline & Frequency $(\%)$ & Frequency $(\%)$ & Frequency $(\%)$ \\
\hline \multicolumn{4}{|l|}{ Gender } \\
\hline Male & 100 & 53 & $153(56.66 \%)$ \\
\hline Female & 61 & 56 & $117(43.34 \%)$ \\
\hline \multicolumn{4}{|l|}{ Education } \\
\hline High school or diploma & 9 & 10 & $19(7.03 \%)$ \\
\hline Bachelor Degree & 79 & 70 & $149(55.19 \%)$ \\
\hline Master or Ph. D. degree & 73 & 29 & $102(37.78 \%)$ \\
\hline \multicolumn{4}{|l|}{ Work experience } \\
\hline Below 5 years & 4 & 8 & $12(4.45 \%)$ \\
\hline $5-10$ years & 20 & 49 & $69(25.55 \%)$ \\
\hline $11-15$ years & 45 & 26 & $71(26.30 \%)$ \\
\hline $16-20$ years & 59 & 17 & $76(28.15 \%)$ \\
\hline Over 20 years & 33 & 9 & $42(15.55 \%)$ \\
\hline \multicolumn{4}{|l|}{ Income (Per Month) } \\
\hline Below 500 USD & 1 & 29 & $30(11.11 \%)$ \\
\hline 501-1000 USD & 23 & 48 & $71(26.30 \%)$ \\
\hline 1001-1500 USD & 61 & 13 & $74(27.41 \%)$ \\
\hline 1501-2000 USD & 55 & 11 & $66(24.44 \%)$ \\
\hline Over 2000 USD & 21 & 8 & $29(10.74 \%)$ \\
\hline Total $(\%)$ & $161(59.62 \%)$ & $109(40.38 \%)$ & $270(100 \%)$ \\
\hline
\end{tabular}

From the Table 1, the most of samples is $59.62 \%$ from Thais and $40.38 \%$ from Laos, $56.66 \%$ male and $43.34 \%$ female, as well as education $7.03 \%$ high school or diploma, 55.19\% Bachelor Degree and $37.78 \%$ master or Ph. D. degree. In terms of work experience, $4.45 \%$ has experience below 5 years, $25.55 \%$ has experience 5-10 years, $26.30 \%$ has experience $11-15$ years, $28.15 \%$ has experience $16-20$ years, and $15.55 \%$ has experience over 20 years. For income side, $11.11 \%$ receive below USD 500 a month, $26.30 \%$ receive USD 501-1000, $27.41 \%$ receive USD 1001-1500, 24.44\% receive USD 1501-2000, and only $10.74 \%$ receive over USD 2000, respectively. 


\section{Result}

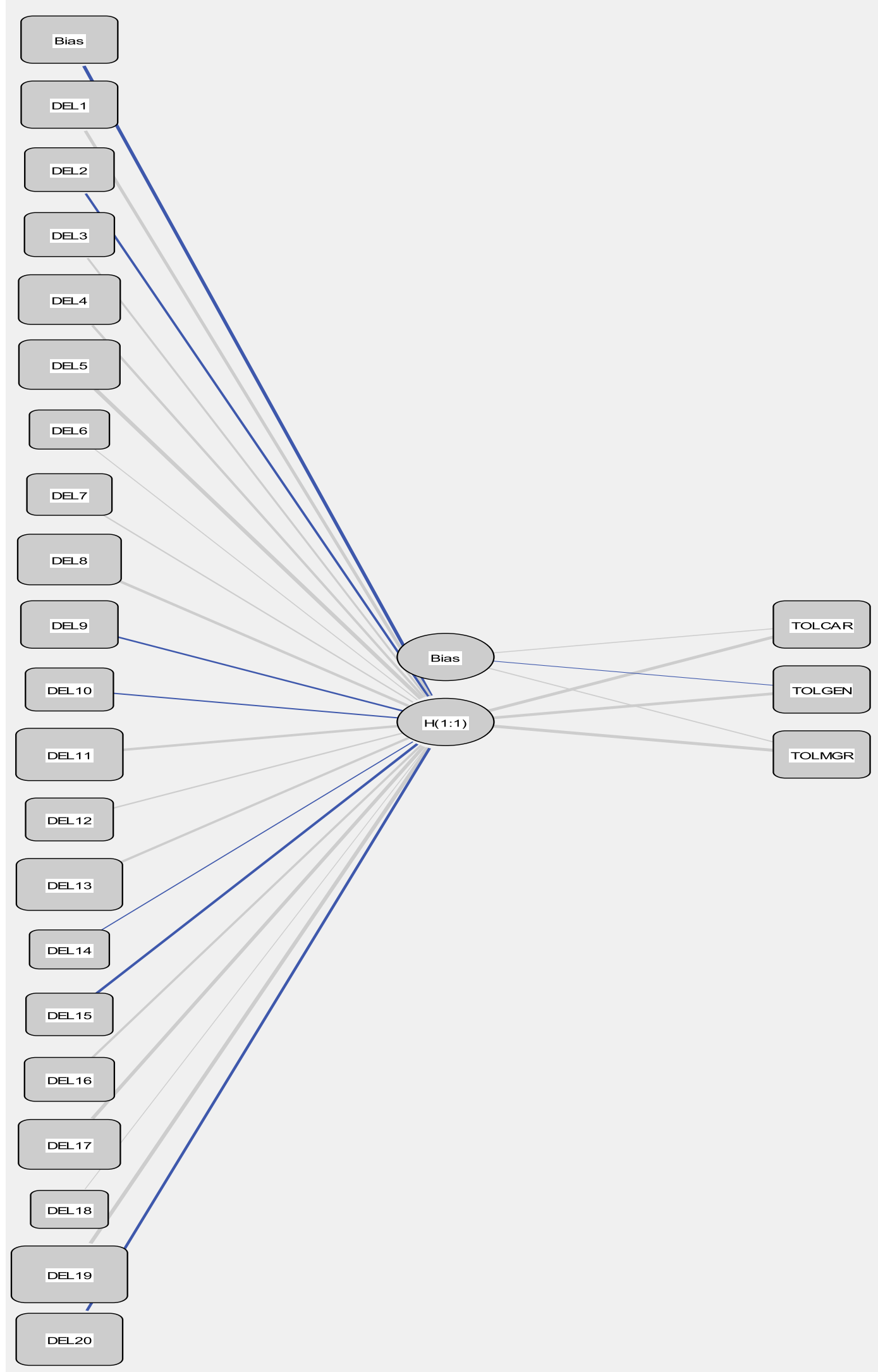

Figure 2. Elements for developing the competency of travel agent manager in Thailand 
From Figure 2, the prioritization of code for the developing the competency of travel agent manager in Thailand can be shown in Figure 3.

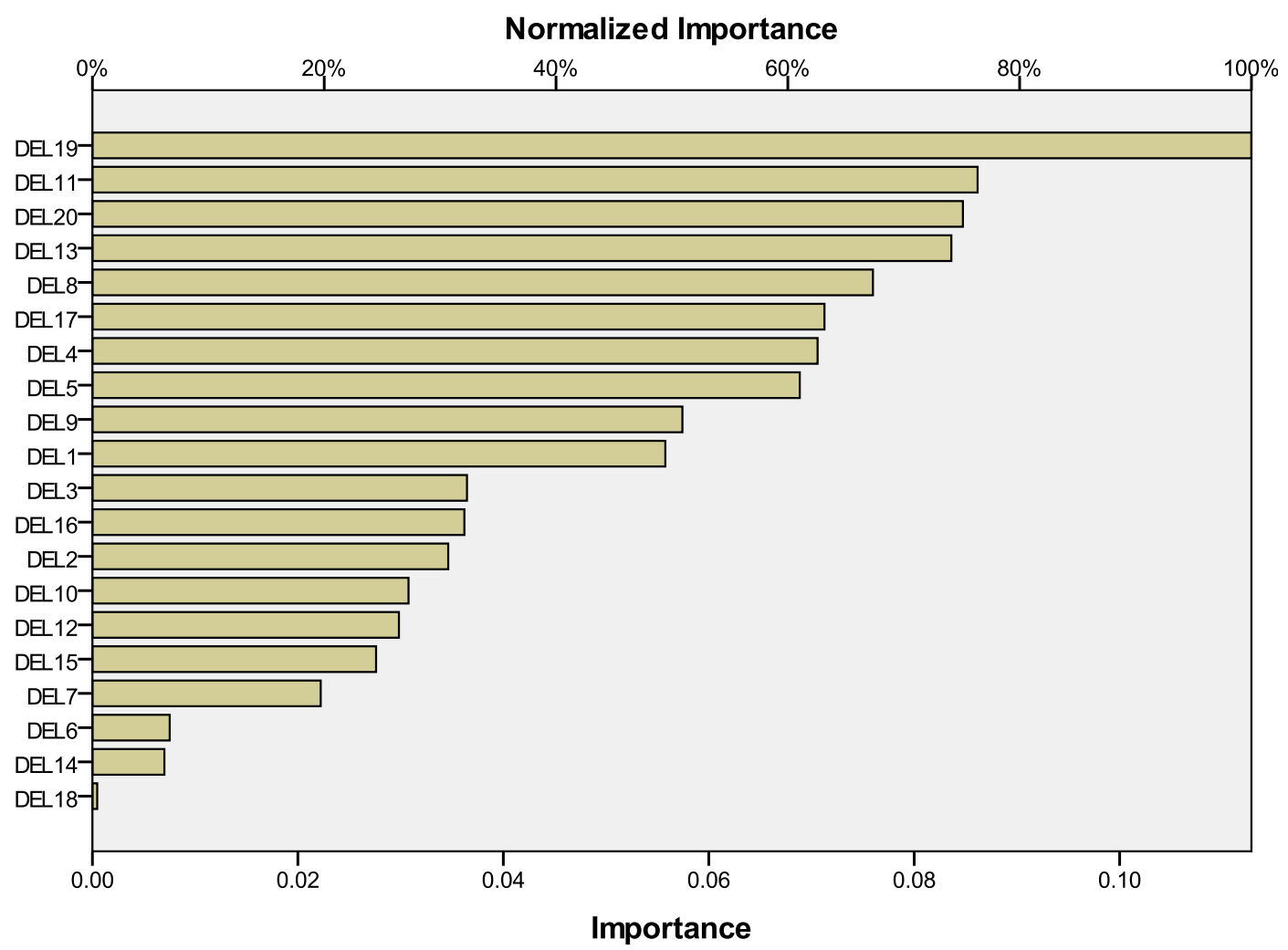

Figure 3. Order of elements for developing the competency of travel agent manager in Thailand (from the most important to the least important)

From Figure 3, it shows that organization culture management (DEL19) is the most important element with the coefficient of $100.00 \%$ followed by change management (DEL11) with the coefficient of $76.40 \%$, self-management (DEL20) with the coefficient of $75.10 \%$, time management (DEL13) with the coefficient of $74.10 \%$, product and service development (DEL8) with the coefficient of $67.30 \%$, learning organization (DEL17) with the coefficient of $63.20 \%$, quality assessment (DEL4) with the coefficient of $62.60 \%$, human resource management (DEL5) with the coefficient of $61.00 \%$, strategic management (DEL9) with the coefficient of 50.90\%, information technology (DEL1) with the coefficient of 49.40\%, financial management (DEL3) with the coefficient of $32.30 \%$, team management (DEL16) with the coefficient of $32.10 \%$, communication skill (DEL2) with the coefficient of $30.70 \%$, work safety (DEL10) with the coefficient of $27.30 \%$, analytical and problem solving skill (DEL12) with the coefficient of $26.40 \%$, quality control (DEL15) with the coefficient of $24.50 \%$, knowledge management (DEL7) with the coefficient of $19.70 \%$, marketing (DEL6) with the coefficient of $6.70 \%$, ethics (DEL14) with the coefficient of $6.20 \%$, and coordination (DEL18) with the coefficient of $0.40 \%$, respectively. 


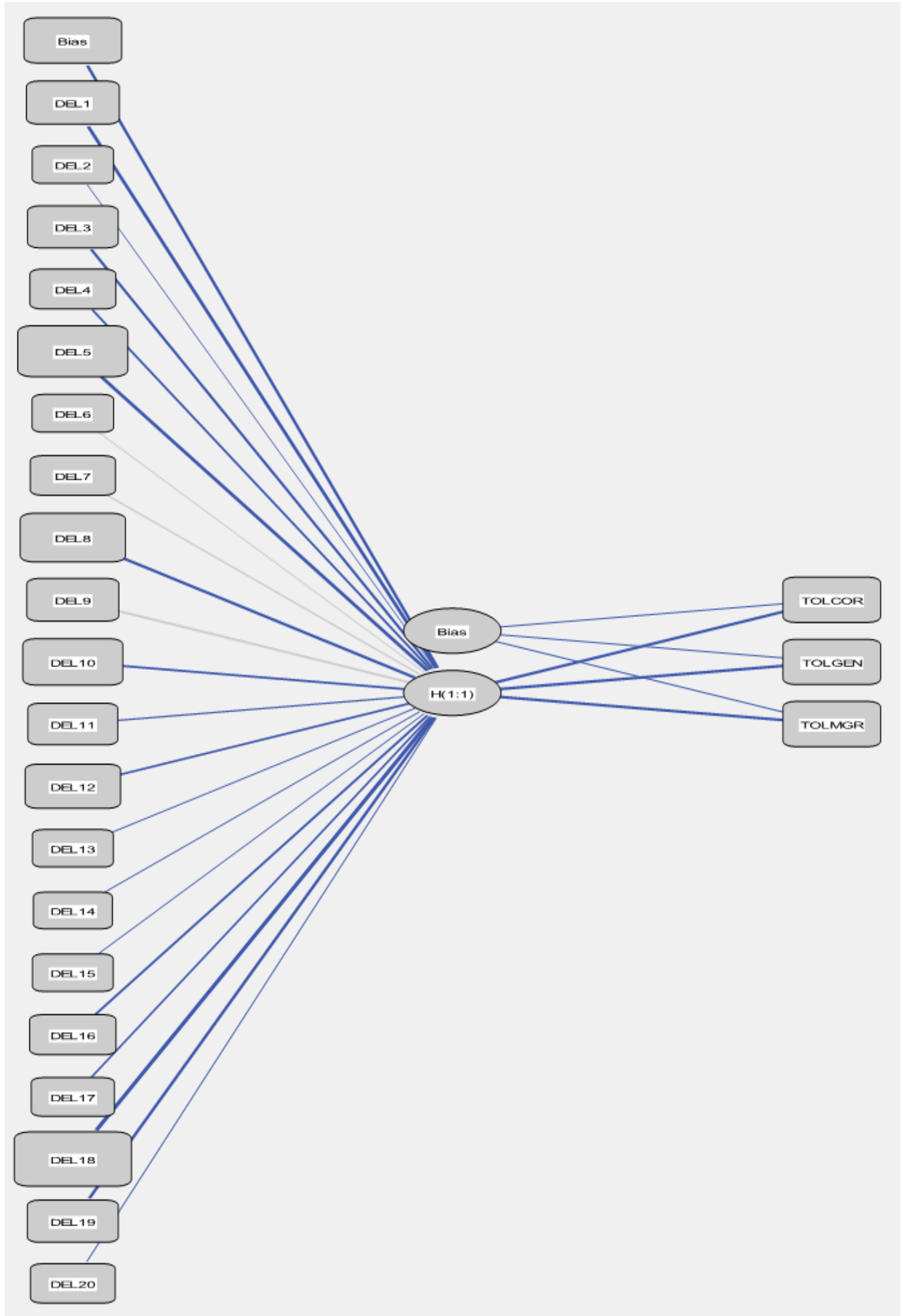

Figure 4. Importance of elements for developing the competency of travel agent manager in Laos

From Figure 4, the prioritization of code for the developing the competency of travel agent manager in Laos can be shown in figure 5 . 


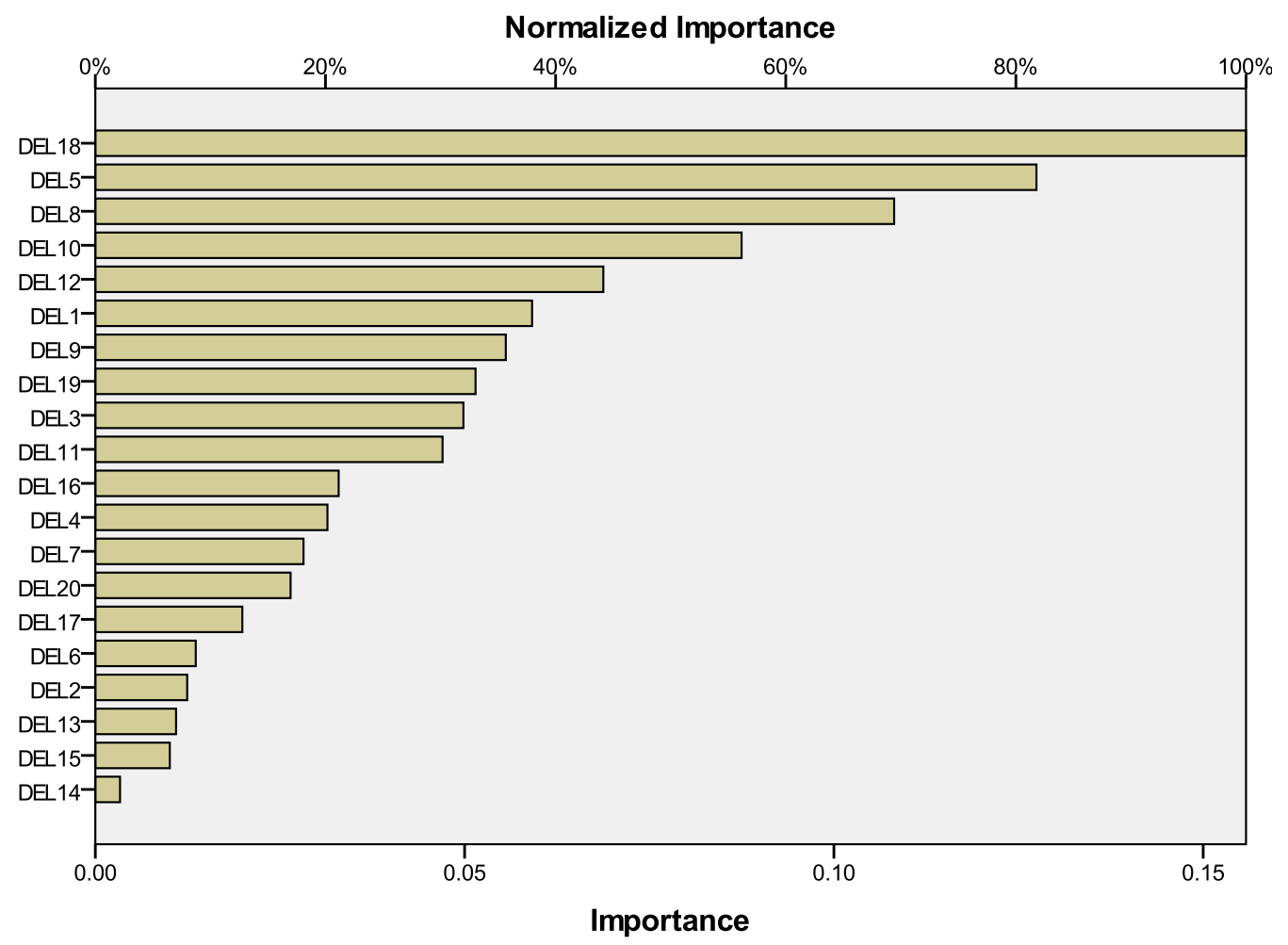

Figure 5. Order of elements for developing the competency of travel agent manager in Laos (From the most important to the least important)

From Figure 5, it shows that coordination (DEL18) is the most important with the coefficient of $100.00 \%$ followed by human resource management (DEL5) with the coefficient of $81.80 \%$, product and service development (DEL8) with the coefficient of $69.40 \%$, work safety (DEL10) with the coefficient of $56.20 \%$, analytical and problem solving skill (DEL12) with the coefficient of 44.10\%, information technology (DEL1) with the coefficient of $38.00 \%$, strategic management (DEL9) with the coefficient of 35.70\%, organization culture management (DEL19) with the coefficient of $33.00 \%$, financial management (DEL3) with the coefficient of 32.00\%, change management (DEL11) with the coefficient of 30.20\%, team management (DEL16) with the coefficient of $21.10 \%$, quality assessment (DEL4) with the coefficient of $20.20 \%$, knowledge management (DEL7) with the coefficient of $18.10 \%$, self-management (DEL20) with the coefficient of $17.00 \%$, learning organization (DEL17) with the coefficient of $12.80 \%$, marketing (DEL6) with the coefficient of $8.70 \%$, communication skill (DEL2) with the coefficient of $8.00 \%$, time management (DEL13) with the coefficient of 700\%, quality control (DEL15) with the coefficient of $6.50 \%$, and ethics (DEL14) with the coefficient of $2.10 \%$, respectively.

\section{Conclusion and Discussion}

From the examination using neural network statistic, the most three important competencies trend to be developed in Thailand and Laos are shown in Table 2.

Table 2. Top three elements to be developed of Thailand and Laos

\begin{tabular}{clcl}
\hline Thailand & Elements to Be Developed & Laos & Elements to Be Developed \\
\hline 1 & Organization culture management & 1 & Coordination \\
2 & Change management & 2 & Human resource management \\
3 & Self-management & 3 & Product and service development \\
\hline
\end{tabular}

From Table 2, data divulge, for Thailand, organization culture is the most important element to be developed because ability to encourage diversity people in the organization to work cooperatively and fairly is one of the 
most important requirements for manager. This is similar to (Kulisha, 2011) work which states that organization culture management allows an individual manager to learn different culture in an organization or different mindset. (Petkovski, 2011), in addition, expresses an opinion on how success of manager depends on how he or she absorb and adapt from one to another culture. For Laos, coordination is the most important element to be developed because if manager can manipulate good cooperation among related parties lead to success and goal achievement. This idea is congruence with (Hannakhin, 2009) stating that effective coordination needs good systemization, practice, and cooperation from many sectors, and it is also coincidental with (Weber et al., 2011) also support that ability to build effective coordination is one of the requirements for travel agent manager.

However, it is unavoidable that change management, which is the second important element for Thai managers, is also significant because nowadays change management conducts more important role in either personal or organizational level than in the past, which is in agreement with (Tanova \& Nadiriwork, 2005) work pointing out that tourism is a enormous industry with a variety of jobs; therefore, change acceptance or ability to deal with change is very important issue to improvement. By the way, (Dhiman, 2012) stated that adjustment for change is a requirement for tourism industry. For Laos, the second important element is human resource management because human capital is priceless involve with recruit, training, performance assessment, retaining, and so on that has a great impact on organization success. (Watson et al., 2004) proposed that human resources management is a significant factor of working process particular in organization. It is in every part of the process starting from recruitment to competency development. (Theppawan, 2011), in the same way, indicated that to be a successful manager, he or she requires knowledge and understanding of human resources management.

The third important element for Thai tourism agent manager is self-management. That is impossible for the manager to function properly when he or she is not able to manage oneself. (Petkovski, 2011) paper, in a similar way, reveals that self-management is a part of emotional intelligence and it plays an important role in identifying the competency required for managing basic function. (Cizel et al., 2007) also state that self-management is an important requirement for a manager because it facilitates to his or her success. For travel agent managers in Laos, product and service development is the third element. This paper point out that differentiate or outstanding characteristic of product and service brings about bigger market share. This is supported by the work of (Whitelaw et al., 2009) reveal that product and service development is a part of management competency. In addition, the findings of (Lertwannawit et al., 2009) work indicate that product and service development should be existed especially in form of road show or off-site campaign.

\subsection{Benefits of the Findings}

1) The findings of this research provide information for examining the travel agent manager competency because nowadays most of small medium enterprise (SME) travel agents in both Thailand and Laos pay a little attention on the development of manager competency; instead, they focus on sales and number of tourists. This may probably be a reason not allowing them to compete with global travel agents and this finally leads to business close down.

2) There are all 20 elements of development which are be significantly, but, from this research, change management development is the most important for Thailand. The sample are more concerned about economic and political changes, thus they agree that tourism must be well-prepared for any change and for serious business competition. On the other hand, in Laos, coordination development is the most important factor for business operation because Lao Association of Travel Agents (LATA) is responsible for private sector operation, the management and coordination is still under the control by Ministry of Information, Culture and Tourism. Both sectors, government and private sector, cannot join as well as it should be.

3) Managers in travel agents can use the findings of this research for improving their competency because it is generally known that working competency augmentation increases competitive advantage not only in domestic level but also in international level. When all ASEAN member countries visibly unite in 2018, the competition in tourism industry will be more seriously because this industry is appointed to be the first pilot business in regional freely opened market. Therefore, if Thai travel agent managers neither adjust themselves nor enlarge their competency, tourism of Thailand will not able to compete with tourism of other countries.

\subsection{Suggestions for Further Studies}

1) Since this research emphasizes only on the travel agent manager competency in Thailand and Laos, to see larger picture of ASEAN tourism, studies of manager competency in other ASEAN member countries should be conducted.

2) To have a broader viewpoint of ASEAN tourism industry and to be able to deal with AEC in 2015 
effectively, studies of competency of other tourism professionals or hospitality business should be conducted.

3) To have information covering the overall tourism industry, studies of competency of professionals in other tourism related businesses should be conducted.

\section{References}

Alonderiene, R., \& Navickiene, R. (2009). Competence development during lifelong learning: The case of front-line employees in Lithuanian tourism sector. Journal of Management and Economics, 18, 12-28.

Boyatzis, R. E. (2008). Competencies in the 21st century. Journal of Management Development, 27(1). http://dx.doi.org/10.1108/02621710810840730

Bunditkul, W. (2012). Roo Chak Prachakom ASEAN (Learn ASEAN translated by the researcher) (2nd ed.). Bangkok: Tawee Print (1991).

Cheng, C. S. (1997). A neural network approach for the analysis of control chart patterns. International Journal of Production Research, 35, 667-697. http://dx.doi.org/002075497195650/10.1080

Cizel, B., Anafarta, N., \& Sarvan, F. (2007). An analysis of managerial competency needs in the Tourism sector: The case of Turkey. Tourism Review, 62(2), 14-22. http://dx.doi.org/10.1108/16605370780000310

Dhiman, M. C. (2012). Employer's perceptions about tourism management employability skill. International Journal of Tourism and Hospitality Research, 23(3), 359-372. http://dx.doi.org/10.1080/13032917.2012.711249

Gaffar, V., \& Setiyorini, D. (2010). Competence development on tourism marketing management study program through soft skills improvement. In International Conference on Technical and Vocational Education and Training, November 10-11, 2010 Bandung Indonesia (pp. 154-164).

Gultek, M. M., Dodd, T. H., \& Guydosh, R. M. (2006). Attitudes towards wine-service training and its influence on restaurant wine sales. International Journal of Hospitality Management, 25, 432-446. http://dx.doi.org/2005.02.001/10.1016

Hannakhin, P. (1999). Experience in personnel management. Bangkok: Chulalongkorn University Press.

Kulisha, I. (2011). Structure of service culture competence of hospitality sector managers. US - China.

Lertwannawit, A., Serirat, S., \& Pholpantin, S. (2009). Career competencies and career success of Thai employees in tourism and hospitality sector. Journal of International Business \& Economics Research, $8(11), 65-72$.

McIntosh, R. W., \& Goeldner, C. R. (1986). Tourism: principles, practices, philosophies (5th ed.). New York: John Wiley \& Sons, Inc.

Meesad, P. (2008). Fuzzy system and artificial neural network. Faculty of Information Technology, King Mongkut's University of Technology North Bangkok.

Ministry of Tourism and Sport. (2011). National Tourism Development Plan 2555-2559.

Moura, M. L. (2013). Tool for quality management: balance and emotional intelligence. African Journal of Hospitality, Tourism and Leisure, 2.

Petkovski, K. (2011). Required skills and leadership characteristics of a modern manager in tourism and hospitality. Journal of Economic, 3, 91-96.

Tesone, D. V., \& Ricci, P. (2005). Attributes of entry-level employees: Hospitality and tourism managers seeking more than knowledge and skills. Journal of Applied Management and Entrepreneurship, 10(2).

Theppawan, P. (2011). Strategic human resources management: concept and strategy of competition advantage. Bangkok: Se-Education Public Company Limited.

Thitthongkam, T., \& Walsh, J. (2010). Role of language in tourism organizational management. Asian Journal of Management Research, 184-199.

Valachis, I. (2003). Essential competencies for a hospitality management career: The role of hospitality management education. Meeting of the Tempus-Phare No CD-JEP 15007/2000 Conference on Educating for Tomorrow's Tourism, Ohrid, Macedonia. 2003.

Watson, S., McCracken, M., \& Hughes, M. (2004). Scottish visitor attractions: managerial competence Requirements. Journal of European Industrial Training, 28(1), 39-66. http://dx.doi.org/10.1108/03090590410513884 
Weber, M. R., Crawford, A., Rivera Jr. D., \& Finley, D. A. (2010). Using delphi panels to assess soft skill competencies in entry level managers. Journal of Tourism Insight, 1(1), 1-9. http://dx.doi.org/10.9707/2328-0824.1011

Whitelaw, P. A., Barron, P., Buultjens, J., Cairncross, G., \& Davidson M. (2009). Training needs of the hospitality industry. CRC for Sustainable Tourism Pty Ltd 2009.

\section{Copyrights}

Copyright for this article is retained by the author(s), with first publication rights granted to the journal.

This is an open-access article distributed under the terms and conditions of the Creative Commons Attribution license (http://creativecommons.org/licenses/by/3.0/). 